\title{
CAPÍTULO 41: ENCAPSULAÇÃO DE ANTIOXIDANTES NATURAIS PARA APLICAÇÃO EM ALIMENTOS: UMA REVISÃO
}

\section{CHAPTER 41: ENCAPSULATION OF NATURAL ANTIOXIDANTS FOR FOOD APPLICATION: A REVIEW}

\author{
Catarina Massena Pires ${ }^{1}$; Érica Santos Pereira ${ }^{2}$; Julia de Souza Amaral ${ }^{3}$; Eliana da Silva Gulão ${ }^{4}$
}

\begin{abstract}
Resumo
A oxidação lipídica é um importante parâmetro de conservação de alimentos, uma vez que altera suas propriedades sensoriais além de gerar a formação de radicais livres. Desta forma, antioxidantes são adicionados ao produto processado, e devido a maior preocupação pela saúde, pesquisas em busca de antioxidantes naturais vêm recebendo destaque. Os compostos bioativos com atividade antioxidante geralmente são instáveis devido a sua estrutura química, nesse sentido as técnicas de encapsulação tornam-se atraentes na preservação destas substâncias. Portanto, o objetivo deste trabalho foi de realizar uma revisão de literatura sobre a oxidação lipídica em alimentos, bem como técnicas de encapsulação para evitar estas alterações. Para realizar a pesquisa foram consultadas as bases Science direct, Scielo e PubMed utilizando as seguintes palavras-chave: encapsulação; microencapsulação; antioxidantes; compostos bioativos. Como resultado, foi observado que diferentes técnicas são aplicadas na encapsulação de antioxidantes, destacando-se as técnicas físicas spray drying e químicas como coacervação complexa e nanoemulsões. Pesquisas demonstram a importância da origem do polímero e núcleo, proporção e fatores como $\mathrm{pH}$ e temperatura a fim de alcançar rendimento e eficiência satisfatórios, além da importância de regular esses fatores de modo a projetar a liberação controlada do núcleo no alimento.
\end{abstract}

\section{Palavras-chave: antioxidantes, compostos bioativos, encapsulação}

\begin{abstract}
\footnotetext{
${ }^{1}$ Estudante de Nutrição. Universidade Estácio de Sá, catarinamassena1 @ gmail.com

${ }^{2}$ Estudante de Nutrição. Universidade Estácio de Sá, ericasantosnf@ hotmail.com

${ }^{3}$ Estudante de Nutrição. Universidade Estácio de Sá, juliasouzaamaral@ gmail.com

${ }^{4}$ Docente. Departamento de Nutrição. Universidade Estácio de Sá, eliana.gulao@estacio.br
}

Lipid oxidation is an important parameter for food conservation, since it alters its sensory properties in addition to generating the formation of free radicals. In this way, antioxidants are added to the processed product, and due to the greater concern for health, research of natural antioxidants has been highlighted. Bioactive compounds with antioxidant activity are generally unstable due to their chemical structure, so encapsulation techniques become attractive in the preservation of these substances. Therefore, the objective of this work was to carry out a literature review on lipid oxidation in foods, as well as encapsulation techniques to avoid these changes. To carry out the research, the databases Science direct, Scielo and PubMed were consulted using the following keywords: encapsulation; microencapsulation; antioxidants; bioactive compounds. As a result, it was observed that different techniques are applied in the encapsulation of antioxidants, highlighting physical techniques spray drying and chemical techniques such as complex coacervation and nanoemulsions. Research demonstrates the importance of the origin of the polymer and core, proportion and factors such as $\mathrm{pH}$ and temperature in order to achieve satisfactory yield and efficiency, in addition 
PIRES, C. M. et al.

to the importance of regulating these factors in order to project the controlled release of the core in the food.

\section{Key-words: antioxidant, bioactive compounds, encapsulation}

\section{Introdução}

A oxidação de lipídios e pigmentos em alimentos é um dos principais parâmetros de deterioração da qualidade de produtos gordurosos e/ou emulsionados, pois leva ao desenvolvimento de odores e sabores desagradáveis e à oxidação de lipídios e pigmentos, afetando negativamente a cor, aparência e aceitabilidade (GALLO; FERRACANE; NAVIGLIO, 2012; WEISS et al., 2010).

Os antioxidantes são adicionados aos alimentos processados para evitar o ranço oxidativo, para retardar o desenvolvimento de sabores indesejáveis e melhorar a estabilidade da cor. Podem ser utilizados tanto antioxidantes naturais como os sintéticos e ambos desempenham um importante papel na produção de alimentos, porém, devido a maior preocupação com a saúde pelos consumidores, têm-se aumentado a preferência pelo uso de antioxidantes naturais, principalmente provenientes de plantas (GALLO; FERRACANE; NAVIGLIO, 2012; JAYATHILAKAN et al., 2007; OHLSSON; BENGTSSON, 2002).

Atualmente produtos industrializados são elaborados com a incorporação de antioxidantes sintéticos, como o eritorbato de sódio, o qual não confere nenhum benefício à saúde do consumidor. Por essa razão, a aplicação do óleo de gengibre em produtos gordurosos e/ou emulsionados pode se tornar uma ideia inovadora, pois além de incorporar um antioxidante eficaz, estará assim obtendo um produto também com função nutritiva. As pesquisas revelaram que, a partir dessas classes, uma série de substâncias possui atividade antioxidante e antibacteriana (BALCÃO et al., 2013; DEANS; RITCHIE, 1987; OHLSSON; BENGTSSON, 2002), no entanto, são substâncias voláteis de difícil aplicação na indústria de alimentos, por isso, a microencapsulação torna-se uma técnica atraente na preservação de compostos instáveis, facilitando sua aplicação nos mais variados setores alimentares (DIMA et al., 2014; DONG et al., 2011).

As propriedades antioxidantes de ingredientes naturais nos produtos podem ser garantidas ao longo da produção e armazenamento do alimento processado por diferentes técnicas de encapsulação. Portanto, o objetivo deste trabalho foi realizar uma revisão de literatura sobre o processo da oxidação em alimentos, bem como da utilização de compostos antioxidantes para controlar tais alterações. Por sua vez, pesquisar através da literatura 
PIRES, C. M. et.al.

científica técnicas de encapsulação utilizadas para facilitar a aplicação destes princípios ativos em alimentos.

\section{Revisão de literatura}

\section{Atividade antioxidante de compostos bioativos em alimentos}

As alterações oxidativas em alimentos referem-se a modificações químicas indesejáveis que se desenvolvem quando o óleo comestível é exposto a fatores como: temperatura, oxigênio, pH, luz, entre outros (YANG et al., 2016). Essas alterações podem ocorrer durante o processamento, o armazenamento, o transporte e no preparo do produto final rico em lipídeos (OANCEA et al., 2018). Com o objetivo de prolongar a vida útil e melhoria da aparência, as indústrias utilizam o mecanismo da atividade antioxidante, um tipo de aditivo alimentar, podendo ser sintético ou natural (SHARMA et al., 2019).

O processo de peroxidação lipídica envolve as fases de iniciação, propagação e terminação. A interação entre o oxigênio triplet, luz e/ou fotossensibilizadores resultam na formação do oxigênio singlete. Este, por sua vez ativado, pode reagir com ácidos graxos insaturados, remover um átomo de hidrogênio do carbono de metileno adjacente à ligação dupla cis do ácido graxo insaturado resultando na formação de radicais livres. Os radicais gerados podem atacar outros ácidos graxos como os produtos formados no início da reação, propagando assim a oxidação. A partir desta etapa a propagação ocorre por meio da reação de radicais livres dos ácidos graxos com o oxigênio ocasionando na formação de radicais peróxidos e hidroperóxidos, insípidos e inodoros. Fatores como o calor, catálise de íons metálicos ou luz pode resultar na decomposição do hidroperóxido, gerando produtos responsáveis pelo odor, sabor e textura característicos do alimento rancificado. Uma vez iniciada, a reação continua em cadeia e termina apenas quando as reservas de ácidos graxos insaturados e oxigênio estão esgotadas. Com o esgotamento dos substratos ocorre a formação de produtos finais estáveis ou não reativos, que compreendem os derivados da decomposição de hidroperóxidos, como álcoois, aldeídos, cetonas, ésteres e outros hidrocarbonetos (RIBEIRO et al., 2019; WANG et al., 2019).

Os antioxidantes naturais, também conhecidos como antioxidantes verdes, são obtidos através de alimentos, especiarias e ervas, são alguns exemplos: alecrim, grão de café, sálvia, alho, tomilho, casca da batata, polpa da beterraba, brócolis, cenoura, aipo, ervilha, cebola e pimenta (BAŞTÜRK et al., 2018).

Nos últimos anos, foram realizados diversos estudos baseados nos antioxidantes naturais, devido à demanda dos consumidores por etiquetas sem aditivos sintéticos, com 
PIRES, C. M. et.al.

estabilidade térmica e dentro das normas de segurança (ALADEDUNYE, 2014; ALADEDUNYE; GRUCZYNSKA, 2018). Sendo assim, foi verificado que o antioxidante natural tem muitas vantagens em relação aos sintéticos, no que diz respeito a sua aceitação, benefícios aos consumidores e sua segurança (BERA; LAHIRI; NAG, 2006). No entanto, a baixa estabilidade, eficácia, baixa solubilidade e alto custo são alguns dos aspetos que limitam sua aplicação nas indústrias (SHARMA et al., 2019). Além disto, a importância dos antioxidantes é reconhecida pela Organização Mundial de Saúde (OMS) que tem argumentado a favor do aumento do consumo mundial de fontes dietéticas de antioxidantes naturais, sendo a ingestão alimentar a principal forma de aquisição desses compostos. A relevância de antioxidantes em organismos vivos, juntamente com o aumento da divulgação na mídia, aumentou os esforços para caracterizar fontes conhecidas de antioxidantes naturais para aplicação em alimentos (LORENZO et al., 2018), neste sentido, pesquisas vêm sendo realizadas para descobrir novas substâncias antioxidantes naturais.

Bera; Lahiri; Nag (2006) compararam a atividade antioxidante do extrato solúvel do cominho ajowan (Carum copticum) com à de antioxidantes sintéticos TBHQ (terc-butilhidroquinona) e BHT (di-terc-butil metil fenol) sobre a oxidação do óleo de palma. Amostras com 100 g do óleo de palma contendo diferentes concentrações dos antioxidantes foram submetidas a variadas temperaturas com o auxílio de um banho termostático, e, a formação de peróxidos acompanhada pelo ensaio de substâncias reativas ao ácido tiobarbitúrico (TBARS). Os autores observaram que todas as substâncias pesquisadas forneceram estabilidade oxidativa até a temperatura de $50^{\circ} \mathrm{C}$ e a partir do aquecimento os antioxidantes sintéticos foram mais eficazes na proteção à oxidação quando comparado ao extrato natural devido à instabilidade dos compostos fenólicos presentes no cominho diante as temperaturas mais altas. Além disso, antioxidantes sintéticos como o TBHQ e BHT possuem atividade primária que retardam ou inibem a etapa de iniciação, reagindo com o radical livre dos lipídios ou inibindo a etapa de propagação reagindo com o radical peroxil ou, radicais alcóxi. Segundo os autores, como a primeira fração do extrato de ajowan contém timol, grupamentos fenólicos em sua estrutura, previnem mais ativamente a oxidação de glicerídeos.

Em uma pesquisa realizada por Baştürk e colaboradores (2018) foi investigada a atividade antioxidante de 6 diferentes ervas: semente de urtiga (Urtica dioica L.), semente de linho (Linum usitatissimum L.), sálvia (Salvia officinalis L.), hortelã (Mentha arvensis L), sumagre (Rhus coriaria L.) e tomilho (Thymus vulgaris). Os autores avaliaram o efeito antioxidante dos extratos de cada erva contra a oxidação do óleo de milho armazenado a $60^{\circ} \mathrm{C}$, comparando seus efeitos com a utilização de antioxidantes já bem empregados: 
palmitato de ascorbila e acetato de tocoferol. As análises foram realizadas no intervalo de 6 semanas através da determinação da atividade antioxidante pelo método DPPH (2,2-difenil1- picril-hidrazil) sendo possível observar maior atividade antioxidante dos extratos de sumagre e palmitato de ascorbila. Ensaios para verificar a estabilidade oxidativa do óleo de milho durante o período de armazenamento também foram realizadas através dos métodos de TBARS, teste de oxidação acelerada (Schaal oven test) dienos e trienos conjugados. Os resultados demonstraram que amostras contendo BHT, sumagre e hortelã foram as responsáveis por maior estabilidade oxidativa do óleo durante o armazenamento do óleo.

\section{Encapsulação: técnicas e materiais}

Devido à grande funcionalidade dos compostos bioativos foi necessário o desenvolvimento de técnicas que aumentassem a sua eficácia e seu tempo de prateleira, garantindo um produto final rico em nutrientes e com estabilidade às condições adversas, sendo uma destas técnicas a encapsulação (ROSSO et al., 2019).

Microencapsulação é o processo pelo qual vários ingredientes alimentícios podem ser armazenados dentro de um invólucro ou revestimento microscópico para proteção e/ou posterior liberação. Mais especificamente, a microencapsulação é o processo de envolver pequenas partículas, um líquido ou um gás, dentro de uma camada de revestimento ou dentro de uma matriz.

Através da encapsulação é possível garantir muitos benefícios, melhorando a qualidade do produto e/ou criando novas aplicações (REBELLO, 2009). Podem ser citados alguns benefícios adquiridos por essa técnica, como: proteção da passagem do nutriente ou composto bioativo pelo sistema gastrointestinal, separação de compostos reativos, liberação controlada ou prolongada, controle de sabores e odores desagradáveis, estabilidade da cor de substâncias instáveis, proteção contra oxidação, diluição de um produto encapsulado em fórmulas alimentares, dentre outros (REBELLO, 2009; ROSSO et al, 2019). Um exemplo é a encapsulação de carotenoides que permite manter a eficácia da funcionalidade de compostos ativos, diminuindo o risco de degradação e oxidação, consequentemente aumentando seu valor nutricional (ROSSO et al, 2019).

As diferentes técnicas de encapsulação se mostram versáteis com aplicação em vários setores, como nas indústrias: farmacêutica, química, alimentícia e agrícola. Uma das razões para o uso desta tecnologia é a proteção de ingredientes, ou seja, evitar a degradação resultante da exposição a fatores ambientais adversos, como água, oxigênio, calor e luz. Tradicionalmente, isto é feito para melhorar o prazo de validade do material ativo (SOBEL; 
VERSIC; GAONKAR, 2014). A facilidade de manuseio é outra razão para encapsular, pois pode ser utilizada como um método simples para converter um ingrediente alimentar líquido em um sólido (pó). A encapsulação pode ser usada para prevenir reações e interações indesejáveis entre ingredientes alimentícios ativos. Além disso, as diferentes técnicas também oferecem a oportunidade de reduzir a volatilidade de vários ingredientes alimentícios, além da possibilidade de controlar a liberação do ativo encapsulado (LIDERT, 2005; MARTÍN et al., 2015; VASISHT, 2014).

Muitas são as técnicas de encapsulação atualmente, mas de forma geral consiste em um núcleo na região central envolvido por uma camada protetora (SILVA et al., 2003). A nomenclatura comum usada para definir as várias partes da cápsula ou esfera formadas inclui a terminologia para o material de revestimento bem como o ingrediente a ser encapsulado. $\mathrm{O}$ ingrediente a ser encapsulado é geralmente chamado de ativo, núcleo, fase interna, encapsulado ou preenchimento. O material que envolve o ativo é comumente chamado de casca, material de parede, revestimento, fase externa, fase de suporte ou membrana. Geralmente, o encapsulaste é insolúvel e não reativo ao núcleo (SOBEL; VERSIC; GAONKAR, 2014; VASISHT, 2014).

Tradicionalmente, a microencapsulação não utiliza cápsulas maiores que $3 \mathrm{~mm}$ de comprimento. De uma forma geral, cápsulas que possuam tamanho em um intervalo de $100 \mathrm{~nm}$ a $1000 \mathrm{~nm}$ são classificadas como microcápsulas e as que possuem tamanho entre $1 \mathrm{~nm}$ e 100nm são classificados como nanocápsulas (SOBEL; VERSIC; GAONKAR, 2014).

As micropartículas são subdivididas em microesferas e microcápsulas, segundo a sua estrutura, como pode ser observado na Figura 1. São denominadas microesferas as partículas compactas constituídas por uma rede polimérica, na qual a substância ativa se encontra distribuída no seu estado sólido ou molecular. Já as microcápsulas, são as partículas constituídas por um núcleo interno, contendo o agente ativo recoberto por uma camada de polímero de espessura variável (GOUIN, 2004). 
Figura 1. Ilustração esquemática representando a estrutura de microcápsulas e microesferas.

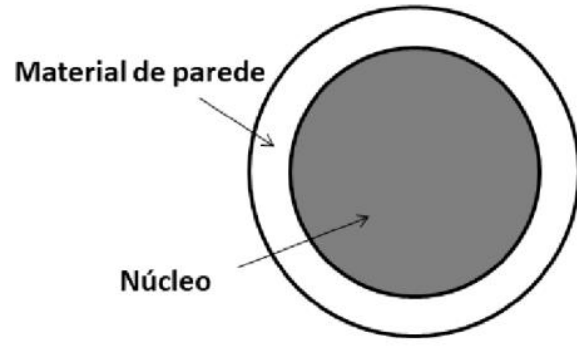

Microcápsula

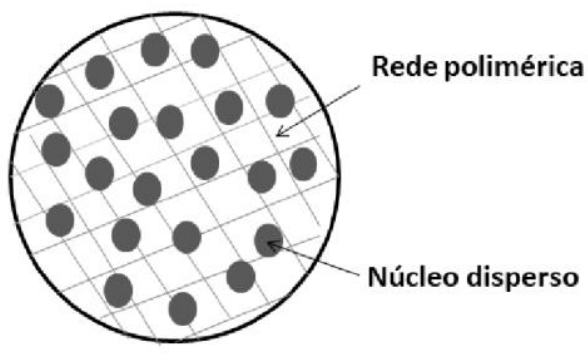

Microesfera

Fonte: Própria, 2018.

Diversos materiais podem ser usados para encapsular podendo estes ser de origem sintética ou natural. Existem algumas características essenciais para encapsulantes, como: ter boa formação de filme, baixa higroscopicidade, baixa viscosidade, sabor e odor suaves, baixo custo, ser insolúvel, liberar o produto ativo em tempo certo, não ser reativo com o núcleo e não ser tóxico. Dificilmente é encontrado um encapsulante com todas essas características, portanto se torna comum o uso de mais de uma substância como filme. A escolha do material vai ser definido a partir do material do núcleo (encapsulado), da escolha da técnica e do objetivo final do produto (PEREIRA et al., 2018). O material de parede é responsável por 1 a $80 \%$ das microcápsulas em peso e podem ser utilizados açúcares, gomas, proteínas, polissacarídeos naturais e modificados, lipídios, ceras e polímeros sintéticos.

O encapsulante deve formar um filme semi-impermeável como, por exemplo, uma membrana celular sem deformações para maior efetividade da retenção do material ativo no núcleo. Essa característica é importante para a proteção do encapsulado e o processo será dependente da concentração da mistura das substância e dos parâmetros do processo de microencapsulação em si, as escolhas serão consideradas adequadas quando formarem micropartículas íntegras, protegendo totalmente o núcleo envolto pelo filme encapsulante (ASCHERI; MARQUEZ; MARTUCCI, 2003).

O amido e seus derivados são considerados bons encapsulantes, pois possuem boa viscosidade e boa solubilidade, podendo ser utilizados na microencapsulação de substâncias voláteis. Uma desvantagem é o seu sabor desagradável, diminuindo a palatabilidade. O amido também, apresenta como desvantagem pouca proteção contra a oxidação de aromatizantes (KRISHNAN et al, 2016). Na utilização de arroz/gelatina como encapsulante observou-se 
PIRES, C. M. et.al.

que as microcápsulas, apesar de serem esféricas e compactas, formam poros, não tendo a formação de uma parede contínua, esses poros podem diminuir a eficácia da microencapsulação, como solução, pode se fazer uma segunda cobertura nas microcápsulas. Com o uso da goma arábica, observou-se a formação de um filme contínuo, sem poros ou rompimentos, ideal para a proteção do núcleo (SANTOS; FÁVARO-TRINDADE; GROSSO, 2005).

O sistema de encapsulação deve ser projetado objetivando um mecanismo de liberação. O núcleo pode ser liberado em diferentes estágios do ciclo de processamento, armazenamento e consumo, e o mecanismo a ser usado dependerá em grande parte do tipo de alimento/bebida e do local em que a carga precisa ser depositada. A água (umidade) é usada como mecanismo de liberação para depositar um ativo durante a reidratação e a dissolução de um pó alimentar quando a água é adicionada, o mesmo é aplicável quando a saliva, dissolvendo um produto alimentar pronto para consumo durante a mastigação. O calor é usado como mecanismo de liberação de um ativo após o aquecimento, cozimento ou tratamento térmico de um produto alimentício como, por exemplo, a adição de água quente ao pó alimentar usado para preparar bebidas quentes (café, chá, achocolatados) e sopas. O cisalhamento mecânico (mastigação) é usado como mecanismo de liberação durante a mastigação de um alimento pronto para o consumo. As enzimas e o pH são utilizados como mecanismo quando um agente ativo tem que ser administrado no trato gastrointestinal (isto é, na boca, no estômago, no intestino delgado ou no cólon), por exemplo, a matriz/material de parede composto por um amido (sensível à amilase na boca) é ideal para a liberação oral. Quando a matriz é composta por proteína a mesma se desintegra na presença de proteases no estômago (GAONKAR, 2014; NAZZARO et al., 2012; PARETA et al., 2014; SOBEL; VERSIC; VASISHT, 2014; YANG et al., 2016). Na indústria alimentícia existe uma grande demanda do uso das técnicas de encapsulação justificado pelo objetivo de manter a estabilidade de compostos instáveis e sensíveis, seja a ação da luz, do ar, do calor ou da água. As substâncias que mais se beneficiam dessa técnica são as oxidantes, vitaminas, ácidos graxos, como ômega 3 e probióticos (DIAS, et al, 2017; ROSSO et al, 2019; SOUZA et al, 2018).

Um estudo utilizando a técnica do spray drying utilizou como encapsulante a goma arábica, considerada um excelente encapsulante devido sua característica de baixa viscosidade em solução aquosa, tendo uma boa capacidade de formar emulsões. Através de pesquisas foi comprovado que possui uma efetiva proteção com relação à atividade oxidante dos óleos essenciais, mas apesar de suas boas características técnicas, a goma arábica possui 
PIRES, C. M. et.al.

um elevado custo limitando assim o seu uso. Em contrapartida, foi analisada também a maltodextrina que tem uma efetiva ação protetora de substâncias antioxidantes, sendo uma opção viável para encapsulação dos óleos essenciais e um custo mais acessível (ABURTO et al, 2009; SANTOS et al, 2005).

O objetivo do produto final será um dos determinantes da técnica escolhida que pode ser física, química ou físico-química. A escolha da técnica leva em conta o material ativo, o encapsulamento, a termossensibilidade e a solubilidade da substância do núcleo. A ação antioxidante, uma das funções mais benéficas das técnicas de encapsulação para compostos ativos está relacionada com a escolha do material encapsulante (OZKAN, 2018).

A oxidação pode ocorrer de duas formas, pela auto-oxidação onde ocorre reação enzimática e ação de radicais livres e pela foto-oxidação, mediada pela ação de raios ultravioletas ou pelo oxigênio. A auto-oxidação forma hidroperóxido lipídico, que pode ser oxidado a cetonas, ésteres, aldeídos, entre outros (CHOE; MIN, 2006). Os óleos essenciais, compostos funcionais muito utilizados no processamento de alimentos, são substâncias propensas a degradação oxidativa, principalmente a ação enzimática (LING, 2015). A oxidação dos óleos comestíveis gera problemas à indústria alimentícia devido à formação de substâncias indesejáveis, causando alteração no sabor, diminuição dos nutrientes e até toxicidade. Uma forma de controlar a ação oxidativa é a adição de substâncias antioxidantes à formulação, um aditivo alimentar usado para prolongar a vida útil do alimento, melhorando a qualidade e a apresentação do produto, consequentemente aumentando seu tempo de prateleira (CHOE; MIN, 2006).

Estudos onde foram realizados a encapsulação de óleos essenciais comestíveis insaturados através da técnica da nanoemulsão, mostraram os benefícios do uso de antioxidantes naturais e antioxidantes sintéticos na formulação de óleos essenciais com o objetivo de proteger da ação oxidativa. Os antioxidantes naturais, como alecrim, sálvia, menta, tomilho, semente de linho, entre outros, possuem mais estabilidade térmica e atividade antioxidante do que os sintéticos, além de potenciais benefícios à saúde. No caso dos óleos essenciais, por serem substâncias com alta volatilidade, ocorre pouca perda nos processos térmicos. Já os antioxidantes sintéticos são utilizados em grande escala devido ao seu baixo custo e ótima eficácia, mesmo sendo prejudiciais à saúde, causando, por exemplo, mutações e tumores (SHARMA et al., 2019).

Os métodos de encapsulação físicos mais utilizados são a atomização pelo spray drying, spray chilling, spray cooling, dextrução centrífuga e liofilização. As técnicas químicas se resumem em polimerização interfacial, indução molecular e polimerização in 
PIRES, C. M. et.al.

situ. Já os métodos físico-químicos incluem coacervação simples, coacervação complexa, emulsões e gelificação iônica (CHAMPAGNE; FUSTIER, 2007). O método escolhido para o processo de microencapsulação deve ser simples, de fácil reprodução, rápido e ser facilmente reproduzido em escala industrial (SILVA et al., 2003). O processo de atomização ou spray drying é um dos mais utilizados na indústria alimentícia devido às vantagens como baixo custo, fácil operação, alta produtividade e facilidade de microencapsulação de substâncias termolábeis. Essa característica relacionada a substâncias termolábeis se explica pelo curto período em que a substância entra em contado com as temperaturas elevadas (NUNES et al, 2018; BURGAIN et al, 2011). O uso de alta temperatura no método de spray drying pode não ser vantajoso para a microencapsulação de probióticos, uma vez que pode causar danos a integridade dos microrganismos, sendo uma solução o uso de encapsulantes termoprotetores visando a preservação da substância probiótica (BURGAIN et al., 2011; GOLOWCZYC et al., 2011; NAZZARO et al., 2012).

Com o avanço da tecnologia há um crescimento do uso da técnica de nanoemulsão, sendo um método de encapsulamento eficaz para substâncias antioxidantes, pois ajudam a melhorar a estabilidade, a solubilidade e a biodisponibilidade dos antioxidantes, além das já conhecidas ações de proteção das técnicas de microencapsulação. As principais vantagens reconhecidas da nanoemulsão são: o baixo uso de surfactante para a formação da emulsão e a grande área de superfície de contato, facilitando o controle da taxa de absorção (SHARMA et al., 2019).

\section{Microencapsulação de antioxidantes para aplicação em alimentos}

Alimentos com alto teor de gordura são suscetíveis a oxidação, que é uma das maiores causas de perdas na indústria (ANDRADE et al., 2019). Para evitar a oxidação de óleos e gorduras é realizada a utilização de aditivos sintéticos que podem apresentar efeito tóxico resultando em potenciais efeitos negativos à saúde. Estudos verificaram que antioxidantes naturais apresentam maior atividade antioxidante e estabilidade térmica comparados aos sintéticos, além vários deles possuírem baixo custo de extração, como partes das plantas de oliveiras, chá verde, gergelim e plantas medicinais (TAGHVAEI; JAFARI, 2015).

A fim de aumentar o tempo de prateleira e diminuir a quantidade de antioxidantes sintéticos estão sendo estudadas opções de embalagens ativas. Embora o grande interesse, existem apenas algumas opções de embalagem disponíveis comercialmente, o que pode ser atribuído às dificuldades na produção dos materiais ativos em escala industrial, à baixa 
PIRES, C. M. et.al.

eficiência da maioria dos materiais desenvolvidos em testes in vivo e à degradação de agentes ativos nos processos de extrusão (WRONA et al., 2017).

Um estudo para retardar a oxidação de gordura natural do salame utilizou um filme ativo de whey protein (isolado proteico do leite) incorporado com extrato de alecrim em embalagens de salame fatiado. Para o extrato de alecrim, $5 \mathrm{~g}$ de alecrim em pó seco foram misturados com $50 \mathrm{~mL}$ de etanol, que foi homogeneizado e evaporado. O filme de proteína de soro de leite foi composto por proteína de soro de leite, glicerol, extrato de alecrim e água ultrapura. O salame foi colocado com os dois lados em contato direto com o filme ativo e o controle (sem o extrato de alecrim), que foram armazenadas à vácuo por diferentes períodos $(0,7,15,30,60$ e 90 dias), protegidos de luz e na temperatura de $5^{\circ} \mathrm{C}$. Como indicador da oxidação lipídica, foram feitas a monitorização hexanal e ensaio TBARS. O outro teste utilizado foi análise sensorial. A embalagem ativa retardou a oxidação em 30 dias além de ter mantido a aparência do produto atraente. Mas, por outro lado, pôde-se perceber um sabor diferente no salame, um amargor que foi atribuído ao extrato de alecrim e um sabor um pouco doce relacionado ao whey e ao glicerol. As análises foram positivas, devendo apenas ser realizada uma análise sensorial mais completa, com maior número de provadores para verificar a aceitabilidade deste filme comestível no mercado (ANDRADE et al., 2019).

Para a embalagem de carne de porco moída fresca foi analisada a incorporação de extrato de chá verde na embalagem de polietileno incorporado em cápsulas inorgânicas ao material derretido e extrudado sem comprometer sua qualidade. Foram utilizadas amostras com $20 \%$ e $40 \%$ de cápsulas ativas e uma amostra sem as cápsulas com o extrato de chá verde, como amostra em branco. As análises foram feitas em triplicata utilizando os métodos DPPH e ensaio de capacidade de absorção de radical de oxigênio (ORAC), realizado pelo método otimizado para analisar a capacidade antioxidante da embalagem. As embalagens foram armazenadas em geladeira a $4{ }^{\circ} \mathrm{C}$ por 13 dias. Após 9 dias de experimento constatouse foi confirmada a liberação de uma pequena porção de agente ativo no nível de polietileno polietilo. A metamioglobina e avaliação sensorial foram significativamente melhores para carne de ambos os tipos de embalagem ativa em comparação com carne de embalagem da amostra sem o composto ativo. Constatou-se que o prazo de validade da carne de porco moída fresca foi estendido por 3 dias, comprovando a capacidade antioxidante da embalagem ativa (WRONA et al., 2017).

Dos Passos et al. (2019) avaliaram o uso de óleo de tomilho como antioxidante natural na maionese em substituição ao antioxidante sintético butilhidroxitolueno (BHT). O óleo de tomilho foi nanoencapsulado em poli $\varepsilon$-caprolactona (PCL) através de suspensão (NP-T) e 
PIRES, C. M. et.al.

foi utilizado uma nanocápsula composta apenas por PCL como amostra de controle (NP-C). O método de nanoprecipitação e o uso do PCL como material de parede proporcionaram nanopartículas contendo altos valores de óleo essencial de tomilho encapsulado com boa estabilidade física. As nanocápsulas foram aplicadas em amostras de maionese. Durante um período de oito dias, as amostras NP-T, NP-C e com antioxidante sintético foram analisadas periodicamente quanto ao valor de hidroperóxido (HP), por titulação e TBARS. Até o terceiro dia de armazenamento, não foram observadas diferenças significativas entre os valores de HP das três amostras. Após seis dias de armazenamento, a amostra sem adição de antioxidante (NP-C) continuou apresentando valores elevados de HP, indicando maior grau de oxidação lipídica enquanto os valores de HP para BHT e NP-T diminuíram. O mesmo ocorreu em relação à análise TBARS, em que as amostras sem antioxidante (NP-C) indicaram a ocorrência de maiores quantidades de malonaldeído. Concluindo que a amostra NP-T teve um desempenho semelhante ao antioxidante sintético BHT na prevenção da oxidação dos lipídios da maionese quanto aos resultados do valor do hidroperóxido (HP) e das substâncias reativas ao ácido tiobarbitúrico (TBARS).

\section{Considerações finais}

Através deste estudo foi possível concluir que a busca por antioxidantes naturais é uma demanda atual e em ascensão pela busca da substituição por antioxidantes sintéticos que não contribuem à saúde. Uma vez que os compostos bioativos advindos de substâncias naturais apresentam menor estabilidade diante a fatores adversos, as diferentes técnicas de encapsulação vêm sendo pesquisadas e cada vez mais aplicadas demonstrando ser uma importante alternativa para preservação destes compostos e facilitar sua aplicação em alimentos, alcançando resultados satisfatórios na preservação da oxidação lipídica. Diferentes técnicas podem ser aplicadas como técnicas físicas e químicas, e fatores como o material encapsulante, proporção, interação entre os polímeros, temperatura e pH devem ser pesquisados a fim de garantir maiores rendimentos e eficiência da encapsulação, além de ser possível projetar uma liberação controlada no alimento e no organismo. Atualmente, as técnicas de microencapsulação através do spray drying e coacervação complexa são as mais utilizadas, porém, técnicas de nanoencapsulação como as nanoemulsões recebem destaque pela possibilidade de maior controle na liberação do princípio ativo no alimento ou no organismo. 


\section{Referências}

ABURTO, L. C.; TAVARES, D. Q.; MARTICCI, T. Microencapsulação de óleo essencial de laranja. Ciência e Tecnologia de Alimentos, v. 18, n. 1, 1998.

ALADEDUNYE, FELIX ADEKUNLE. Natural antioxidants as stabilizers of frying oils. European Journal of Lipid Science and Technology, v. 116, n. 6, p. 688-706, 2014. DOI: 10.1002/ej1t.201300267.

ANDRADE, MARIANA A.; RIBEIRO-SANTOS, REGIANE; GUERRA, MANUELA; SANCHES-SILVA, ANA. Evaluation of the oxidative status of salami packaged with an active whey protein film. Foods, v. 8, n. 9, p. 1-15, 2019. DOI: 10.3390/foods8090387.

ASCHERI, DIEGO P. R.; MARQUEZ, MÁRCIA O. M.; MARTUCCI, ENNY T. Microencapsulação de óleo essencial de laranja: seleção de material de parede. Ciência e Tecnologia de Alimentos, v. 23, p. 1-6, 2003. DOI:10.1590/s0101-20612003000400002.

ASSIS, L. M.; ZAVAREZE, E. R.; PRENTICE-HERNANDEZ, C.; SOUZA- SOARES, L. A. Características de nanopartículas e potenciais de aplicações em alimentos. Brazilian Journal Food Technology, v. 15, n. 2, p. 99-109, 2012.

BALCÃO, VICTOR M.; COSTA, CARLA I.; MATOS, CARLA M.; MOUTINHO, CARLA G.; AMORIM, MANUELA; PINTADO, MANUELA E.; GOMES, ANA P.; VILA, MARTA M.; TEIXEIRA, JOSÉ A. Nanoencapsulation of bovine lactoferrin for food and biopharmaceutical applications. Food Hydrocolloids, v. 32, n. 2, p. 425-431, 2013. DOI: 10.1016/j.foodhyd.2013.02.004.

BAKRY, A. M.; ABBAS, S.; ALI, B.; MAJEED, H.; ABOUELWAFA, M. Y.; MOUSA, A.; LIANG, L. Microencapsulation of pila: a comprehensive review of benefits, techniques and applications. Comprehensive Reviews in Food Science and Food Safety, v. 15, n. 1, p. 143-182, 2015.

BAŞTÜRK, AYHAN; CEYLAN, MEHMET MURAT; ÇAVUŞ, MUSTAFA; BORAN, GÖKHAN; JAVIDIPOUR, ISSA. Effects of some herbal extracts on oxidative stability of corn oil under accelerated oxidation conditions in comparison with some commonly used antioxidants. LWT - Food Science and Technology, v. 89, p. 358-364, 2018. DOI: 10.1016/j.lwt.2017.11.005.

BERA, D.; LAHIRI, D.; NAG, A. Studies on a natural antioxidant for stabilization of edible oil and comparison with synthetic antioxidants. Journal of Food Engineering, v. 74, n. 4, p. 542-545, 2006. DOI: 10.1016/j.jfoodeng.2005.03.042.

BURGAIN, J.; GAIANI, C.; LINDER, M.; SCHER, J. Encapsulation of probiotic living cells: From laboratory scale to industrial applications. Journal of Food Engineering, v. 104, no. 4, p. 467-483, 2011. DOI 10.1016/j.jfoodeng.2010.12.031.

CHAKKARAVARTHI, S. Efficacy of free and encapsulated natural antioxidants in oxidative stability of edible oil: Special emphasis on nanoemulsion-based encapsulation. Trends in Food Science and Technology, v. 91, p. 305-318, 2019. DOI: 10.1016/j.tifs.2019.07.030.

CHAMPAGNE, CLAUDE P.; FUSTIER, PATRICK. Microencapsulation for the improved [631] 
delivery of bioactive compounds into foods. Current Opinion in Biotechnology, v. 18, n. 2, p. 184-190, 2007. DOI: 10.1016/J.COPBIO.2007.03.001.

CHOE, EUNOK; MIN, DAVID B. Mechanisms and factors for edible oil oxidation. Comprehensive Reviews in Food Science and Food Safety, v. 5, n. 4, p. 169-186, 2006.

DEANS, S. G.; RITCHIE, G. Antibacterial properties of plant essential oils. International Journal of Food Microbiology, v. 5, n. 2, p. 165-180, $1987 . \quad$ DOI: http://dx.doi.org/10.1016/0168-1605(87)90034-1.

DIAS, D.R.; BOTREL, D.A.; FERNANDES, R.V. Encapsulation as a tool for bioprocessing of functional foods. Current Opinion in Food Science, v.13, p. 31-37, 2017. DOI: 10.1016/j.cofs.2017.02.001.

DIMA, CRISTIAN; COTÂRLET, MIHAELA; ALEXE, PETRU; DIMA, STEFAN. Microencapsulation of essential oil of pimento [Pimenta dioica (L) Merr.] by chitosan/kcarrageenan complex coacervation method. Innovative Food Science \& Emerging Technologies, v. 22, p. 203-211, 2014. DOI: http://dx.doi.org/10.1016/j.ifset.2013.12.020.

DONG, ZHIJIAN; MA, YONG; HAYAT, KHIZAR; JIA, CHENGSHENG; XIA, SHUQIN; ZHANG, XIAOMING. Morphology and release profile of microcapsules encapsulating peppermint oil by complex coacervation. Journal of Food Engineering, v. 104, n. 3, p. 455460, 2011. DOI: 10.1016/j.jfoodeng.2011.01.011.

DOS PASSOS, RHAYSA BEATRIZ; BAZZO, GIOVANA CAROLINA; ALMEIDA, ALINE DA ROSA; NORONHA, CAROLINA MONTANHEIRO; BARRETO, PEDRO LUIZ MANIQUE. Evaluation of oxidative stability of mayonnaise containing poly $\varepsilon$ caprolactone nanoparticles loaded with thyme essential oil. Brazilian Journal of Pharmaceutical Sciences, vol. 55, p. 1-6, 2019. DOI: 10.1590/s2175-97902019000118177.

ENACHI, ELENA; BAHRIM, GABRIELA; RÂPEANU, GABRIELA; SILVI, STEFANIA; STĂNCIUC, NICOLETA. Functional evaluation of microencapsulated anthocyanins from sour cherries skins extract in whey proteins isolate. LWT v. 95, p. 129-134, 2018. DOI: 10.1016/j.lwt.2018.04.083.

GALLO, MONICA; FERRACANE, ROSALIA; NAVIGLIO, DANIELE. Antioxidant addition to prevent lipid and protein oxidation in chicken meat mixed with supercritical extracts of Echinacea angustifolia. The Journal of Supercritical Fluids, v. 72, n. 0, p. 198204, 2012. DOI: 10.1016/j.supflu.2012.08.006.

GOUIN, SÉBASTIEN. Microencapsulation: industrial appraisal of existing technologies and trends. Trends in Food Science \& Technology, v. 15, n. 7-8, p. 330-347, 2004. DOI: 10.1016/J.TIFS.2003.10.005.

GOLOWCZYC, MARINA A.; SILVA, JOANA; TEIXEIRA, PAULA; DE ANTONI, GRACIELA L.; ABRAHAM, ANALÍA G. Cellular injuries of spray-dried Lactobacillus spp. isolated from kefir and their impact on probiotic properties. International Journal of Food Microbiology, v. 144, n. 3, p. 556-560, 2011. DOI: 10.1016/j.ijfoodmicro.2010.11.005.

GÓMEZ, Belén; BARBA, Francisco J.; DOMÍNGUEZ, Rubén; PUTNIK, Predrag; BURSAĆ KOVAČEVIĆ, Danijela; PATEIRO, Mirian; TOLDRÁ, Fidel; LORENZO, Jose 
M. Microencapsulation of antioxidant compounds through innovative technologies and its specific application in meat processing. Trends in Food Science and Technology, v. 82, p. 135-147, 2018. DOI 10.1016/j.tifs.2018.10.006.

JAYATHILAKAN, K.; SHARMA, G. K.; RADHAKRISHNA, K.; BAWA, A. S. Effect of natural antioxidants on the lipid stability of fluidised bed-dried mutton. Food Chemistry, v. 100, n. 2, p. 662-668, 2007. DOI: 10.1016/j.foodchem.2005.09.083.

KRISHNAN, S.; BGOSALE, R.; SINGHAL, R. S. Microencapsulation of cardamomo oleoresin: Evaluation of blends of gum arabic maltodextrina and a medições starch as wall materials. Carbohydrate Polymers, v. 61, n. 1, p. 95- 102, 2005 . DOI: 10.1016/j.carbpol.2005.02.020

LIDERT, ZEV. MICROENCAPSULATION: AN OVERVIEW OF THE TECHNOLOGY LANDSCAPE. IN: ROSEN, MEYER R. Delivery System Handbook for Personal Care and Cosmetic Products. Norwich, NY: William Andrew Publishing, 2005. p. 181-190. DOI: 10.1016/B978-081551504-3.50013-4.

LING, T. Oxidation of polyunsaturated fatty acids and its impact on food quality and human health. Advances in Food Technology and Nutritional Sciences, v. 1, n.6, p. 135-142, 2015. DOI: 10.17140/AFTNSOJ-1-123.

LORENZO, J. M.; MUNEKATA, P. E. S.; GÓMEZ, B.; BARBA, F. J.; MORA, L.; PÉREZSANTAESCOLÁSTICA, C.; TOLDRÁ, F. Bioactive peptides as natural antioxidants in food products - A review. Trends in Food Science and Technology, v. 78, p. 136-147, 2018. DOI: 10.1016/j.tifs.2018.07.003.

MARTÍN, MARÍA JOSÉ; LARA-VILLOSLADA， FEDERICO; RUIZ, MARÍA ADOLFINA; MORALES, MARÍA ENCARNACIÓN. Microencapsulation of bacteria: A review of different technologies and their impact on the probiotic effects. Innovative Food Science \& Emerging Technologies, v. 27, p. 15-25, 2015. DOI: /10.1016/j.ifset.2014.09.010.

NAZZARO, FILOMENA; ORLANDO, PIERANGELO; FRATIANNI, FLORINDA; COPPOLA, RAFFAELE. Microencapsulation in food science and biotechnology. Current Opinion in Biotechnology, v. 23, n. 2, p. 182-186, 2012. DOI 10.1016/j.copbio.2011.10.001.

NUNES, G. L. N.; SILVA, T. M.; HOLKEM, A. T.; SCHLEY, V.; MENEZES, C. R.. Microencapsulação de culturas probióticas: princípios do método de spray drying. Ciência e Natura, v. 37, p. 132-141, 2015. DOI: 10.5902/2179-460X19742

OANCEA, A.; HASAN, MAHADI; VASILE, AIDA MIHAELA; BARBU, VASILICA; ENACHI, ELENA; BAHRIM, GABRIELA; RÂPEANU, GABRIELA; SILVI, STEFANIA; STĂNCIUC, NICOLETA. Functional evaluation of microencapsulated anthocyanins from sour cherries skins extract in whey proteins isolate. LWT, v. 95, p. 129-134, 2018. DOI: 10.1016/j.lwt.2018.04.083.

OHLSSON, THOMAS; BENGTSSON, NILS. Minimal processing technologies in the food industries: Woodhead Publishing, 2002. 
OZKAN, G et al. A review of microencapsulation methods for food antioxidante: principles, advantages, drawbacks and applications. Food Chemistry, p. 494 - 506, 2019. DOI: 10.1016/j.foodchem.2018.07.205.

PEREIRA, K. C.; MOTA-FERREIRA, D. C.; ALVARENGA, G. F.; SALVADOR P.; SANTANA, M.; SOUTO B. M. C.; GOMES, C. J. M.. Microencapsulation and release controlled by the diffusion of food ingredients produced by spray drying: A review. Brazilian Journal of Food Technology, vol. 21, 2018. DOI:10.1590/1981-6723.08317.

PLESSAS, S.; BOSNEA, L.; ALEXOPOULOS, A.; BEZIRTZOGLOU, E. Potential effects of probiotics in cheese and yogurt production: A review. Engineering in Life Sciences, v. 12, p. 433-440, 2012. DOI: 10.1002/elsc.201100122.

REBELLO, F. F. P. Microencapsulação de ingredientes alimentícios. Revista Agrogeoambiental, v. 1, n.3 2009. DOI: 10.18406/2316-1817v1n32009223

RIBEIRO, J. S.; SANTOS, M. J. M. C.; SILVA, L. K. R.; PEREIRA, L. C. L.; SANTOS, I. A.; DA SILVA, L., SUZANA, C.; DA SILVA, M. V.. Natural antioxidants used in meat products: A brief review. Meat Science, v.148, p. 181-188, 2019. DOI: 10.1016/j.meatsci.2018.10.016.

ROSENBERG, M.; YOUNG, S. Whey proteins as microencapsulating agents. Microencapsulation of anhydrous milk fat-structure evaluation. Food Structure, v. 12, p. 31-41, 1993. DOI: 10.3168/jds.S0022-0302(93)77625-0.

ROSSO, A. C.; KUZNIEWSKI, F. C.; GRIESANG, J. I.; BERTOLDO, V.; CRISTINA; OLIVEIRA, M. S.; SEVERO, J.. Boletim Técnico-Científico| Boletim Técnico-Científico, v. 5 n. 2, 2019. Disponível em: http://periodicos.iffarroupilha.edu.br/index.php/boletimtecnico-cientifico/issue/view/Boletim Técnico-Científico.

SHAHIDI, F.; HAN, X. Encapsulation do food ingredients. Critical Reviews in Food Science and Nutrition, v. 33, n.6, p. 501-547, 1993.

SANTOS, A. B. FAVARO-TRINDADE, C. S.; GROSSO, C. R. F. Preparo e caracterização de microcápsulas de oleoresina de páprica obtidas por atomização. Ciência e Tecnologia de Alimentos., v. 25, n. 2, p. 322- 326, 2005. DOI: 10.1590/S0101-20612005000200024.

SILVA, C.; RIBEIRO, A.; FERREIRA, D.; VEIGA, F. Administração oral de proteínas é peptídeos: II. Aplicação de métodos de microencapsulação. Brazilian Journal of Pharmaceutical Sciences, v. 39, n. 1, p. 1-9, 2003. DOI: 10.1590/S151693322003000100002.

SHAHIDI, FEREIDOON; HAN, XIAO QING. Encapsulation of Food Ingredients. Critical Reviews in Food Science and Nutrition, v. 33, no. 6, p. 501-547, 1993. DOI: $10.1080 / 10408399309527645$.

SHARMA, S.; CHENG, S. F.; BHATTACHARYA, B.; CHAKKARAVARTHI, S. Efficacy of free and encapsulated natural antioxidants in oxidative stability of edible oil: Special emphasis on nanoemulsion-based encapsulation. Trends in Food Science and Technology, v. 91, p. 305-318, 2019. DOI: 10.1016/j.tifs.2019.07.030.

SILVA, C.; RIBEIRO, A.; FERREIRA, D.; VEIGA, F.. Administração oral de peptídeos e 
proteínas: II. Aplicação de métodos de microencapsulação. Revista Brasileira de Ciências Farmacêuticas, v. 39, p. 1-20, 2003. DOI: 10.1590/s1516-93322003000100002.

SOBEL, R.; VERSIC, R.; GAONKAR, A. G.. Introduction to Microencapsulation and controlled delivery in foods. Microencapsulation in the Food Industry, 2014. p. 3-12. DOI:10.1016/B978-0-12-404568-2.00001-7.

SOUZA, A. L. R.; HIDALGO-CHAVEZ, D. E.; PONTES, S. M. GOMES, F. S., CABRAL, L. M. C.; TONON, R. V. Microencapsulation boy spray drying of a lycopene-rich Tomato concentrate: characterization and stability. Lebensmittel- wissenschaft technologie, v. 91, p. 286-292, 2018.

TAGHVAEI, MOSTAFA; JAFARI, SEID MAHDI. Application and stability of natural antioxidants in edible oils in order to substitute synthetic additives. Journal of Food Science and Technology, v. 52 p. 1272-1282, 2015. DOI: 10.1007/s13197-013-1080-1.

VASISHT, NIRAJ. Selection of Materials for Microencapsulation. Microencapsulation in the Food Industry, 2014. p. 173-180. DOI: 10.1016/B978-0-12-404568-2.00016-9.

WANG, C.; WANG, H.; LI, X.; ZHANG, C.. Effects of oxygen concentration in modified atmosphere packaging on water holding capacity of pork steaks. Meat Science, v. 148, p. 189-197, 2019. DOI: 10.1016/j.meatsci.2018.10.001.

WEISS, J.; GIBIS, M.; SCHUH, V.; SALMINEN, H.. Advances in ingredient and processing systems for meat and meat products. Meat Science, v. 86, n. 1, p. 196-213, 2010. DOI: 10.1016/j.meatsci.2010.05.008.

WRONA, M.; NERÍN, C.; ALFONSO, M. J.; CABALLERO, M. A.. Antioxidant packaging with encapsulated green tea for fresh minced meat. Innovative Food Science and Emerging Technologies, v. 41, p. 307-313, 2017. DOI 10.1016/j.ifset.2017.04.001.

DIMA, C.; PĂTRAŞCUA, L.; CANTARAGIU, ; PETRU, A.; ŞTEFAN, D.. The kinetics of the swelling process and the release mechanisms of Coriandrum sativum L. essential oil from chitosan/alginate/inulin microcapsules. Food Chemistry v. 195, p. 39-48, 2016. DOI: 10.1016/j.foodchem.2015.05.044. 